\title{
Supporting the Use of Environmental Information Systems and Services - Experiences with a Course for Postgraduate Professional Education
}

\author{
Roman Lenz, Werner Rolf, and Christian Tilk \\ University of Applied Sciences, Nürtingen-Geislingen, \\ Schelmenwasen 4-8, D-72622 Nürtingen
}

\begin{abstract}
At our University we developed a course for further training and professional education in landscape and environmental planning, commenced in 2001 [1]. The main content are Geographical Information Systems (GIS), Data Management Systems, and Visualisation. We introduce relevant software, but apply and teach them from a landscape planning point of view. The course has three weeks of joint training, with partly online-guided self-study phases of four weeks in between. Our clients are mainly professionals from governmental organizations, as well as freelancers. Interestingly, the course helps us to improve our curriculum for Bachelor and Master nowadays [2]. Hence, we believe, the course contains as well as continuously updates somehow the most important digital methods and tools in Landscape Planning, strongly related to current and on-going changes of professional needs. One of those needs is certainly the increasing use of Environmental Information Systems and Services.
\end{abstract}

Keywords: Environmental Information Systems, further education, Geographical Information Systems, Environmental Informatics.

\section{Introduction}

In the last years at Nürtingen-Geislingen University a course for further training and professional education in landscape and environmental planning was developed. This course is taught in German and called „Geodatenmanager Umwelt“. It's part of the advanced education programme „U3 - Umweltinformatik Unterricht für Umweltplaner" which focuses on the topics of Geographical Information Systems (GIS), Data Management Systems, and Visualisation [1], [3].

The course introduces into relevant software, but apply and teach them from a landscape planning point of view. The course has two weeks of joint training, with partly online-guided self-study phases of four weeks. Clients are mainly professionals from governmental organizations, as well as freelancers. In addition, we often have some graduate students as tutors, who are interested in problem solving approaches of professionals as well as in more sophisticated GIS applications and other digital methods. The professionals not only benefit from updated methods and tools, but also from the skills and knowledge of the students. Interestingly, the course becomes more and more an update of what was offered already during the diploma or bachelor 
studies in Landscape Planning at our University, and, vice versa, helps us to improve our curriculum for Bachelor and Master nowadays (e. g. [2]). Hence, we believe, the course contains as well as continuously updates somehow the most important digital methods and tools in Landscape Planning, strongly related to current and on-going changes of professional needs. In other words, courses for professional education, together with academic curricula, support each other's.

In the following we describe the course development over the last 10 years, and the current competence focus as well as different learning methods and tools that can be seen as an selection of the best established methods of the programmes evolution.

After more than a dozen courses we also have had many evaluations, which show the feedback of students and professionals that will be presented besides some, proven applications useful for teaching applied GIS methods.

Because new developments took place in the most recent years this is not an update of a description published earlier [1], but will also lead to new conclusions. Therefore the outlook will contain hints that may inspire other programmes on how digital methods can be taught rather advanced and "with all senses" in universities curricula of landscape planning.

\section{Programme Description}

\subsection{Course Development}

This professional education programme evolved as a consequence of a course that was originally developed for students with whom a problem orientated approach was trained.

From 1996 until 2000, within the project "ECCEI - European Canadian Curriculum on Environmental Informatics" international students from Germany, Italy and Canada, coming from faculties of different disciplines (informatics and environmental management) were trained to find IT based solutions for environmental issues [4]. Core element of ECCEI was the so called "Short Alpine Course on Environmental Informatics - SACEI" whereas the Soelk Valley in the central alps (Austria) was the training field for environmentally relevant issues that had to be solved within a one week summer school like workshop.

Although the concept originally was thought to educate students, in the year 2001 the methodological-didactical approach was tested for first time as a training course for professionals named "U3 - Environmental Informatics Education for Environmental Planners". To apply this approach to the needs of professional's further presence modules and online modules for self-study phases and training were developed and combined. The outcome was an in-service training programme of four-month duration. The applied use of GIS, database, visualisation and Internet technologies was the focus.

After 4 courses with 77 participants the programme became "U3plus". The concept changed in the way that now professionals and students were now together course participants. The idea was to offer students the opportunity to learn more about the 
practical needs and applied IT use and to deepen their interest in environmental informatics beyond the universities curriculum. On the other hand the professionals should benefit from the advanced GIS skills and knowledge of the students, and could fill out a tutor like role. Within the next years three courses with 10 students and 44 professionals took place.

In 2007 the concept was updated again. The complete programme was divided into single specific issues and the modules got a more stringent structure. The training programme "U3" was therefore separated into different parts. The main course is now named "U3-Geodata-Manager Environment". It's an in-service training lasting three month and does have a very strong GIS focus. Other course contents (like database, internet technologies etc.) were extracted into single outlook course modules (each of a weekend duration) called "U3-Extensions". Last ones could be optionally chosen on single topics offered. However the problem orientated approach with a one-week workshop like situation still remains as a characteristic of the methodologicaldidactical concept in form of a single one-week workshop-like module as part of the "U3-Geodata-Manager Environment" training programme.

Since that time another 77 participants, almost every tenth of them were students, summing the number of participants up to 208 in the past ten years, were visiting the "U3" programme.

\subsection{Competence Focus - Learning Goals}

Learning goal is the use of Information Technologies (IT) within the field of environmental planning and resource management, with a focus on Geographical Information Systems (GIS). Within the course usually ArcGIS in its most actual version is being used as an example, but other software solutions, especially Open Source GIS, are being used as well.

\begin{tabular}{|c|c|c|}
\hline \multirow{2}{*}{$\begin{array}{l}\text { Introduction } \\
\text { Seminar }\end{array}$} & $\begin{array}{l}\text { - Introduction in GIS within the context of environmental } \\
\text { informatics and its use for environmental planners }\end{array}$ & $\begin{array}{l}\text { Online Module } \\
\text { Workload: } 10 \mathrm{~h}\end{array}$ \\
\hline & $\begin{array}{l}\text { - Exemplary exercises of different project phases to deepen } \\
\text { comprehension of GIS use in practise for "green jobs" }\end{array}$ & $\begin{array}{l}\text { Presence Module } \\
\text { Workload: } 6 \mathrm{~h}\end{array}$ \\
\hline \multirow{2}{*}{$\begin{array}{l}\text { Basic } \\
\text { Seminar }\end{array}$} & $\begin{array}{l}\text { - Overview and practical use of GIS methods and tools } \\
\text { (data management, capturing, analysis, presentation) }\end{array}$ & $\begin{array}{l}\text { Presence Module } \\
\text { Workload: } 24 \mathrm{~h}\end{array}$ \\
\hline & - Training and exercise of the tools in use & $\begin{array}{l}\text { Online Module } \\
\text { Workload } 20 \mathrm{~h}\end{array}$ \\
\hline $\begin{array}{l}\text { Practical } \\
\text { Seminar }\end{array}$ & $\begin{array}{l}\text { - Learning an appropriate and efficient use of GIS methods } \\
\text { and tools within an environmental project } \\
\text { (incl. data and project management as well as } \\
\text { integrated use of complementary IT solutions) }\end{array}$ & $\begin{array}{l}\text { Presence Module } \\
\text { Workload: } 40 \mathrm{~h}\end{array}$ \\
\hline $\begin{array}{l}\text { Outlook } \\
\text { Seminars/ } \\
\text { Extensions }\end{array}$ & $\begin{array}{l}\text { - Overview and practical use of optionally choosen additional } \\
\text { and complementary IT tools and methods } \\
\text { (CAD, internet and database technologies, mobile services,..) }\end{array}$ & $\begin{array}{l}\text { Presence Module } \\
\text { Workload: } 12 \mathrm{~h}\end{array}$ \\
\hline
\end{tabular}

Fig. 1. Different modules with their main learning goals 
The participants should get a practice relevant overview of the most important methods and tools and gain ability to break down planning issues for IT based solutions. Herewith participants should be enabled to perform basic applications on their own but also achieve ability to discuss more complex issues with experts. This involves to estimate quality aspects, validity of models as well as management abilities. The relevant issues are split into several different modules (Fig. 1).

The learning goals can be associated to different aspects as follows.

\section{Appropriate and efficient use of GIS tools and methods}

Participants get an overview of practice relevant GIS tools and methods for data management, data capturing, data analysis and presentation. The aspect of data capturing includes quality aspects of geo data, quality check and quality improvement. Data analysis contains attribute and spatial analysis of vector and raster data as well as data derivation due to geoprocessing and data modelling. This includes documentation aspects for comprehensibility of manipulated GIS data and to keep transparency of data analysis and modelling for further decision-making processes.

\section{Data Management}

This means participants learn how an efficient data management is being organised, taking into account different conditions, i.e. integrated use of geo data server for multiple users etc. Besides that they get introduced into relevant environmental geo data from different sources and in different scales and learn how to handle a combined use. Data documentation with metadata can be associated to this topic as well.

\section{Project Management}

This involves learning how to approach and transform environmental planning issues for IT processing and the implementation of the appropriate methods and tools. Therefore it is important to know how to design a GIS project, and how to structure and document it. Within the course participants become aware of potentials and limitations of GIS software and learn appropriate complementary other IT tools like interactive visualisation systems.

\subsection{Teaching Approach - Learning Methods and Tools}

The course is set up as a blended learning concept [5]. Several online and presence modules complete the programme (Fig 1.). Hence, we believe that transfer of knowledge can be organized more efficiently while separating lessons with teaching attendance from exercises and study parts were the personal needs of the participants may differ regarding time requirements. Besides that it offers more flexibility in timetabling of course work, which is an essential requirement of an in-service course programme and accommodates to the needs of participants that cannot be absent from business for a longer time [6], [7]. Therefore three different main methods can be distinguished: 


\section{1) Teacher-centred lectures with tutor supported exercise blocks}

Particularly lessons in which basic knowledge will be introduced are preferred to be taught in teacher-centred lectures [8]. Exemplary, short, tutored exercise blocks usually go along with them. In this way participants learn the principles and get familiar with the software use as well. In this combination this method is used as a key to access prior knowledge. Like a colourful flower bouquet being presented it offers the possibility to negotiate the wide range of methods and tools but the lecturer still has the opportunity to respond on specific interests of the participants, depending on their field of practise.

During the exercise blocks students support the course participants as tutors. As they are usually advanced in the use of GIS tools because of the universities curricula, they can help the professional participants by the software use. In preparation on this the student tutors coincidentally have to self-reflect their knowledge to identify own knowledge gaps and finally to resolve them. In this way this methods helps them as well to enlarge their own knowledge.

\section{2) Problem orientated approach, project work within working groups}

This, more or less, is one of the main characteristics of the U3 programme and in particular of the so-called "practical seminar". Here the participants are faced with a real world problem and the task is to "solve this problem" with the help of IT. i.e. GIS [9]. As a first step groups are build perspective the level of profession and/or regarding the interest of deepening certain methods. This will lead to a process that we call an internal differentiation among the heterogeneous participants, as within more homogenous teams learning goals can be achieved more efficient [10], [11]. The only preset is that the groups have to be mixed with students and professional participants together, so they can both learn from each other during the project work.

During the project work the different teams will get individual support by the lecturers, who now have the task of supervisors. Just in case one or more groups end up in a situation where new fundamental knowledge on specific methods or tools are needed theoretical parts are taught with short information blocks as "Lectures on the fly".

After this module of each working group a study is expected that will be presented by the end of the practical seminar. Besides the approach and solution being presented the assignment has to contain as brief description of the used methods and tools as well as possible traps, problems and workarounds.

As case studies several planning tasks are given as choice, that are prepared already in a way that they offer the use of a wide range of methods and tools. Nevertheless the participants usually are developing own project ideas as well.

\section{3) Online-guided self-study phases}

Besides the presence modules several online modules are implemented, which are strongly e-learning supported. The main tool for our online modules is the so called 
U3-Learning-Management-Platform (U3-Imp), a database once designed for the course needs and realized by programming with PHP and MySQL. The U3-Imp can be accessed via in the Internet. Participants have a personalised user account and will guide after login through a user friendly front-end. An additional mailing list, realised with Majordomo, supports the communication among the participants. Via the backend an administrator is able to organize the participants in different courses and modules, i.e. users, roles and courses can be managed quite easily.

Within the modules different themes can be created where the lecturers assigned to the theme can upload the lessons and tasks. The participants again can upload their results topic associated. The working results can be shared with other co-authors, so that even group work can be done. Furthermore a course blackboard is included besides simple true and false self-tests. Last ones do not have any automated analyses functions integrated, as they are used mainly for self-evaluation through the participants themselves.

Some of the tools can be described similar to common e-learning platform functions of adding, editing, organising resources, learning materials and assignments [12], [13]. Such as discussion forums, chat rooms and web-conferences or grade items are not supported. Even though being aware that other e-learning software packages on the market already offer far more sophisticated options and additional tools, the focus of our work was set on the preparation of suitable learning contents. They exist out of learning materials, tasks, sample data and step-by-step solutions. The material is conceived to prepare course participants to a defined common knowledge background in preparation to an up-coming presence module as well as to recapitulate and exercise lessons learned during the presence modules as a post-process.

Anyhow, because the U3-Imp has, from the technical point of view, not been significantly developed since implementation in 2001 - which is one year before the first Moodle version 1.0 was placed on the marked, in August 2002 [14] - it's most likely to replace it in near future, probably as soon as at our university a university wide elearning platform is widely accepted and used.

\section{Programme Results}

\subsection{Outcome of Project Work}

Within the last years many different projects were worked out. At best, the issue meets the interest of the participant:

- From the thematic point of view (f.i. because of the professional specification).

- From the technical point of view (f.i. because of the intention to learn specific methods and tools)

Table 1 contains a compilation that gives an idea about the thematic spectrum and the used methods as well as being used in the past courses. 
Table 1. Overview of different projects and their thematic spectrum

(* VD= Vector Data GIS methods; $\mathrm{RD}=$ Raster Data GIS methods; $\mathrm{MG}=$ Mobile GIS components; $\mathrm{WG}=$ Web-GIS components; 3D=3D-visulisation technologies, $\mathrm{DB}=$ with integrated database interface)

\begin{tabular}{|c|c|c|c|c|c|c|}
\hline \multirow[t]{2}{*}{ Project title/Thematic issue } & \multicolumn{6}{|c|}{$\begin{array}{l}\text { Used GIS methods } \\
\text { and complementary components* }\end{array}$} \\
\hline & VD & $\mathrm{RD}$ & MG & WG & $3 \mathrm{D}$ & DB \\
\hline $\begin{array}{l}\text { Analysis of a biotope } \\
\text { connectivity system in for } \\
\text { different habitat types }\end{array}$ & $\mathbf{x}$ & $\mathbf{x}$ & & & & \\
\hline $\begin{array}{l}\text { Analysis of landscape } \\
\text { structures to support habitat } \\
\text { connectivity for moor lands }\end{array}$ & $\mathbf{x}$ & $\mathbf{x}$ & & & & \\
\hline $\begin{array}{l}\text { Analysis and models to detect } \\
\text { potential sites for wind power } \\
\text { plants }\end{array}$ & $\mathbf{x}$ & $\mathbf{x}$ & & & $\mathbf{x}$ & \\
\hline $\begin{array}{l}\text { Analysis to identify different } \\
\text { thematic landscape scenery } \\
\text { tours for tourism }\end{array}$ & $\mathbf{x}$ & $\mathbf{x}$ & & & $\mathbf{x}$ & \\
\hline $\begin{array}{l}\text { Development of an internet } \\
\text { based information system for } \\
\text { biking routes }\end{array}$ & $\mathbf{x}$ & $\mathbf{x}$ & & $\mathbf{x}$ & $\mathbf{x}$ & \\
\hline $\begin{array}{l}\text { Development of an geo data } \\
\text { service for the administration }\end{array}$ & $\mathbf{x}$ & $\mathbf{x}$ & & $\mathbf{x}$ & & \\
\hline $\begin{array}{l}\text { Development of a GIS } \\
\text { supported field mapping } \\
\text { method for a biotope register }\end{array}$ & $\mathbf{x}$ & & $\mathbf{x}$ & & & \\
\hline $\begin{array}{l}\text { Development of a mobile } \\
\text { touring guide for landscape } \\
\text { exploration }\end{array}$ & $\mathbf{x}$ & & $\mathbf{x}$ & & & \\
\hline $\begin{array}{l}\text { Development of a hiking } \\
\text { information system for } \\
\text { different user groups }\end{array}$ & $\mathbf{x}$ & & & & & $\mathbf{x}$ \\
\hline $\begin{array}{l}\text { Design of an information } \\
\text { system for biotope } \\
\text { management }\end{array}$ & $\mathbf{x}$ & & & & & $\mathbf{x}$ \\
\hline
\end{tabular}

\subsection{Evaluation Results}

During the years the courses an internal evaluation was done by the end of each course. Around Three aspects of this evaluation will be presented: 


\begin{tabular}{|l|l|}
\hline & Disagree \\
\hline $\begin{array}{l}\text { a) The Contents improve my } \\
\text { professional qualification as an } \\
\text { environmental planner }\end{array}$ & \\
\hline $\begin{array}{l}\text { b) Contents could been transferred into } \\
\text { professional practice during course } \\
\text { already }\end{array}$ & \\
\hline $\begin{array}{l}\text { c) The Practice seminar is very useful } \\
\text { and should, from the conceptual } \\
\text { design, kept }\end{array}$ & \\
\hline $\begin{array}{l}\text { d) To reach learning goals the } \\
\text { conditions at university would be } \\
\text { adequate enough }\end{array}$ & \\
\hline $\begin{array}{l}\text { e) Mixed groups, } \\
\text { students+professionals, contribute to } \\
\text { make the course a success }\end{array}$ & \\
\hline
\end{tabular}

Fig. 2. Evaluation sheets tallied (2a-2d: 123 evaluated participants out of 10 courses; 2e: 69 evaluated participants out of 5 courses)

\section{The practical relevance of the course contents}

Because the programmes alignment is profession orientated and the target group of environmental planners is clearly defined, it is not very surprising that almost none denied that this course improves the professional qualification as an environmental planner (Fig. 2a). More interesting seems the feedback to the question if the learned topics could contribute to perform tasks in the daily business of profession, while the course is still running (Fig. 2b). More than half of the participants could transfer the lessons learned right away.

\section{The methodological-didactic approach of the practical seminar - module 2}

More than $90 \%$ of the enumerated questionnaires agree that this module should be kept as it is (Fig. 2c). Furthermore about $70 \%$ doubt that the same learning goals could have been reached with conditions at the university (Fig. 2d). Here the question focused on the situation of working together for one week in teams within a seminar building - away but on site - instead of a regular seminar situation on campus. Here participants often mention that the flexibility of the schedule for the working groups is one practical point to make the learning process productive. Besides that, the intense atmosphere and the option to compare the digital data models with the real world during a field trip also helps to get a better impression of data significance and validity.

Furthermore the working progress was evaluated during the seminars using a mood-barometer, which is supposed to document the atmosphere within the different working groups. Every participant was asked to mark two times a day (around noon and in the evening) his personal satisfaction with a point on a scale. In the context of the working group the supervisors use these marks as an indication about the progress within the different groups. A look at them shows that it is fairly uncommon that there is a steady increasing satisfaction among group members. It's more or less an up and 
down, which is documenting success and achievement as well as setbacks. In any case, if at the end of the course the line shows up again it's most likely that satisfied project result and therefore learning goals have been achieved (Fig 3).

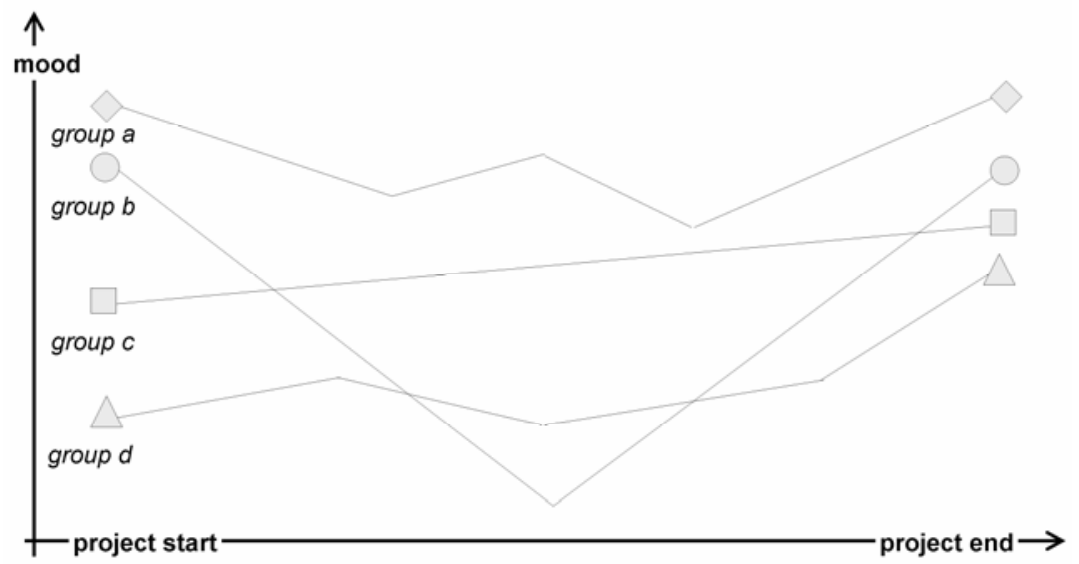

Fig. 3. Schematised figure of evaluated mood-barometers, documented during the practical seminar, may indicate the progress of the working group and achievement of the learning goals.

\section{The effect of students and professionals working/learning together}

Although just half of the courses could be evaluated from this aspect (see course development at 2.1), the majority of the participants clearly agree to the idea of mixed groups and to the fact that quality of the course would benefit due to this (Fig. 2e). Students often mentioned to appreciate to learn from the structural approach of the professionals and also to get a better impression of practice relevance of GIS. Professionals on the other hand find the time with students not just refreshing for the atmosphere but also benefit from their experience and skills in the use of GIS.

\section{The efficiency of the e-learning module}

Although this aspect was never structurally evaluated by the questionnaire the results and outcomes as well as the debriefing of the online module allow some conclusions. Therefore professionals appreciate the option to recapitulate lessons from the presence modules and to take time to exercise regarding their personal needs. The contents were evaluated as suitable and effective particularly for post-processed recapitulation of lessons learned and for exercising.

On the other hand the discussions have shown, that it needs a lot of self-discipline and therefore online modules are sometimes neglected, in particular during work intense times, as lots of participants are freelancers. Because of this we discussed with participants again and again if a more compulsory assignments would enforce attendance. But usually those ideas are rejected as being too school-like. One option to increase motivation during online modules is seen in more interactive face-to-face communication tools (like virtual team rooms) and periodic meetings. 


\section{Benefits to the educational quality for students of the landscape architecture faculty}

Especially during the first years synergy effects between the programme development and the development of the faculties GIS curriculum took place and indeed still do. This is owed to the fact that the assistants of the faculties GIS laboratory were involved in the programme development and therefore could test new approaches and teaching methods. Later, after GIS introduction was an integral part of the general studies the introduction module was not being considered as a course to teach students basic elements rather an option to deepen them. In the first view years this effect could be observed quite well. Besides the majority of the students may got introduction on GIS basics always a few used the offer to get familiar with more sophisticated GIS applications. But particularly since transition form diploma to bachelor programme this positive effect fails to appear. From personal discussion we know that this occurs because of inconvenient time frames and the tight studies timetable. Therefore the willingness to attend at courses outside classes seems to decrease significantly.

\section{Conclusions and Outlook}

Especially the central part of the programme of joint training, the so-called "Practical Seminar", is well appreciated. But this is not just because we run a "real world project" but also because our classroom for this week is on a remote place of the Swabian Alb, where we live and work together - very often until late in the evening. This "summer school like" situation - mainly in the winter season - communicates in an excellent way the various ways of learning, and often brings group members together, who have similar interests and knowledge backgrounds. This so called internal differentiation, combined with the general blended learning concept during the whole course, proved to be quite successful and effective.

10 years of experiences with e-learning methods again and again make us learn that even well evaluated and accepted learning materials are half worth of it, if learning motivation will not constantly raised. This is even more important for an inservice training programme. Therefore interactive tools, like virtual team rooms and regular meetings seem to be essential.

Regarding the students decreasing willingness to attend at courses outside classes due to new time conditions new stimuli needs to be thought about to increase interest again for more sophisticated GIS applications that go beyond the basic GIS curriculum of the faculties. Those can be seen for instance in new corporation forms between the programme and the faculty, i.e. if project and study area of the practical seminar relate to students semester project. Especially in combination with professionals working together at the practical seminars would be mutually beneficial.

\section{References}

1. Rolf, W., Lenz, R.: U3-Umweltinformatik-Unterricht für Umweltplaner - Ein Fort- und Weiterbildungskonzept an der Hochschule für Wirtschaft und Umwelt NürtingenGeislingen. In: Geoforschungszentrum Potsdam (Hrsg.): Innovationen in der Aus- und Weiterbildung mit GIS, Potsdam, Tagungsband, CD-ROM, Juni 2-3 (2005) 
2. Lenz, R.: The IMLA study program: how to strengthen methodology in Landscape Architecture. In: A Critical Light on Landscape Architecture, Proceedings ECLAS Conference 2004, As, Norwegen, September 16-19 (2004)

3. Lenz, R., Rolf, W.: U3 - Umweltinformatikunterricht für Umweltplaner - oder: Lernen mit allen Sinnen. In: Studienkommission Für Hochschuldidaktik An Fachhochschulen In Baden-Württemberg (Hrsg.): Beiträge zum 5. Tag der Lehre, Fachhochschule Nürtingen, Karlsruhe, pp. 174-176 (2003)

4. Lenz, R.J.M.: Project Overview European-Canadian-Curriculum on Environmental Informatics (ECCEI). In: Proceedings International Transdisciplinary Conference, Zürich (2000)

5. Schmidt, I.: Blended E-Learning: Strategie, Konzeption, Praxis. Diploma Thesis. HS Bonn-Rhein-Sieg. Publ.: Examicus, p. 105 (2005)

6. Wiepke, C.: Computergestützte Lernkonzepte und deren Evaluation in der Weiterbildung Blended Learning zur Förderung von Gender Mainstreaming. Studien zur Erwachsenenbildung, Bd.23, p. 342. Kovac-Verlag, Hamburg (2006)

7. Sauter, A.M., Sauter, W.: Blended Learning. In: Effiziente Integration von E-Learning und Präsenztraining, p. 344. Hermann Luchterhand Verlag, Neuwied (2002)

8. Gudjons, H.: Frontalunterricht - neu entdeckt: Integration in offene Unterrichtsformen, p. 227. UTB, Stuttgart (2007)

9. Blötz, U.: Planspiele in der beruflichen Bildung, p. 271. Bertelsmann, Bielefeld (2008)

10. Schittko, K.: Differenzierung in Schule und Unterricht. Ziele - Konzepte - Beispiele, p. 202. Ehrenwirth Verlag, München (1991)

11. Klein-Landeck, M.: Differenzierung und Individualisierung beim offenen Arbeiten. Beispiel: Englischunterricht. Pädagogik 56(12), 30-33 (2004)

12. Bett, K., Wedekind, J.: Lernplattformen in der Praxis, p. 248. Waxmann Verlag, Münster (2003)

13. Grünwald, S.: Learning Management Systeme im universitären Betrieb, p. 224. Lulu, Deutschland (2008)

14. Hoeksemann, K., Kuhn, M.: Unterrichten mit Moodle. In: Praktische Einführung in das ETeaching, p. 229. Open Source Press, München (2008) 